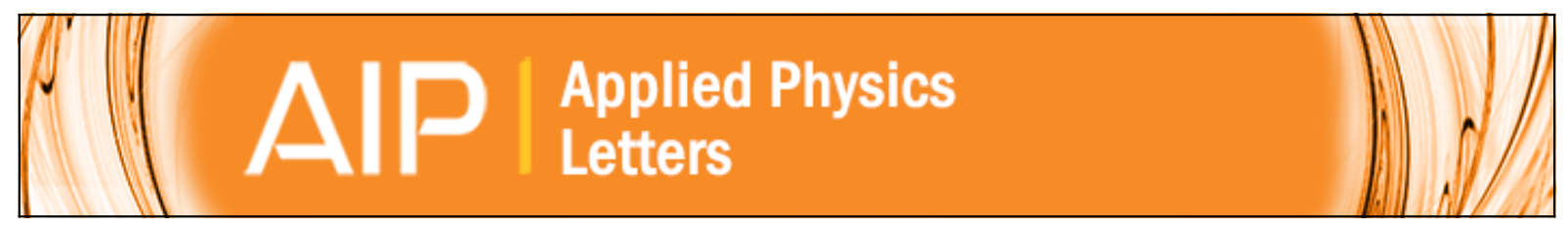

\title{
Sb-mediated growth of Si-doped AIGaAs by molecular-beam epitaxy
}

Yu. G. Sadofyev, S. R. Johnson, S. A. Chaparro, Y. Cao, D. Ding, J.-B. Wang, K. Franzreb, and Y.-H. Zhang

Citation: Applied Physics Letters 84, 3546 (2004); doi: 10.1063/1.1715153

View online: http://dx.doi.org/10.1063/1.1715153

View Table of Contents: http://scitation.aip.org/content/aip/journal/apl/84/18?ver=pdfcov

Published by the AIP Publishing

\section{Articles you may be interested in}

The role of $\mathrm{Si}$ as surfactant and donor in molecular-beam epitaxy of AIN

J. Appl. Phys. 98, 093508 (2005); 10.1063/1.2126786

Highly Si-doped AIN grown by plasma-assisted molecular-beam epitaxy

Appl. Phys. Lett. 86, 192108 (2005); 10.1063/1.1923180

$\mathrm{Sb}$ surfactant effect on GalnAs/GaAs highly strained quantum well lasers emitting at $1200 \mathrm{~nm}$ range grown by molecular beam epitaxy

J. Appl. Phys. 96, 44 (2004); 10.1063/1.1760841

Sb-mediated growth of $\mathrm{n}$ - and $\mathrm{p}$-type AIGaAs by molecular beam epitaxy

J. Vac. Sci. Technol. B 22, 1436 (2004); 10.1116/1.1705579

Si doping for $\mathrm{n}$ - and p-type conduction in Al x Ga 1-x As grown on GaAs(311)A by molecular-beam epitaxy

J. Appl. Phys. 93, 2638 (2003); 10.1063/1.1539912 


\title{
Sb-mediated growth of Si-doped AIGaAs by molecular-beam epitaxy
}

\author{
Yu. G. Sadofyev, S. R. Johnson, ${ }^{\text {a) }}$ S. A. Chaparro, ${ }^{\text {b) }}$ Y. Cao, D. Ding, J.-B. Wang, \\ K. Franzreb, and Y.-H. Zhang \\ Center for Solid State Electronics Research and Department of Electrical Engineering, \\ Arizona State University, Tempe, Arizona 85287-6206
}

(Received 26 September 2003; accepted 27 February 2004; published online 20 April 2004)

\begin{abstract}
The Sb-mediated growth of $\mathrm{Al}_{0.65} \mathrm{Ga}_{0.35} \mathrm{As}$ is studied for $\mathrm{Sb} / \mathrm{III}$ flux ratios from 0 to $2 \%$ and growth temperatures from 580 to $720^{\circ} \mathrm{C}$. The electrical properties and surface morphology are found to depend strongly on both the growth temperature and the $\mathrm{Sb}$ flux. As an isoelectronic dopant, $\mathrm{Sb}$ improves the conductivity of $n-\mathrm{Al}_{0.65} \mathrm{Ga}_{0.35} \mathrm{As}$ with the highest conductivities occurring at the highest growth temperatures. As a surfactant, $\mathrm{Sb}$ improves the surface morphology at all growth temperatures, with the most dramatic improvement occurring at $670^{\circ} \mathrm{C}$. The smoothest surface $(0.2$ $\mathrm{nm}$ rms roughness) was obtained at $700^{\circ} \mathrm{C}$ using a Sb/III flux ratio of 0.02 . Furthermore, we have demonstrated that the use of $\mathrm{Sb}$ during the molecular-beam-epitaxy growth of AlGaAs effectively eliminates the "forbidden temperature gap." (C) 2004 American Institute of Physics.
\end{abstract}

[DOI: $10.1063 / 1.1715153]$

The existence of a forbidden substrate temperature gap for the growth of AlGaAs layers by molecular-beam epitaxy (MBE) has been widely reported. ${ }^{1-3}$ The surface morphology of $\mathrm{Al}_{x} \mathrm{Ga}_{1-x} \mathrm{As}(x>0.2)$ is smooth for lower growth temperatures $\left(550-600^{\circ} \mathrm{C}\right)$, rough for intermediate temperatures $\left(620-680^{\circ} \mathrm{C}\right)$, and smooth for high temperatures $\left(700-750^{\circ} \mathrm{C}\right)$. These temperature ranges vary slightly with aluminum composition. The lower growth temperatures result in epitaxial layers with smooth surface morphology that have less than optimal electrical properties compared to layers grown at higher temperatures. Moreover, at the highest growth temperatures the sticking coefficient of $\mathrm{Ga}$ is less than unity and strongly dependent on growth temperature, resulting in poor composition control. Such a poor control of growth becomes crucial for devices such as vertical-cavity surface-emitting lasers (VCSELs), in which both accurate control of growth rate and interface roughness are critical to the device performance. Therefore, one has to compromise when choosing an adequate growth temperature for GaAs/ AlGaAs distributed Bragg reflectors in a VCSEL. Sb as a surfactant has been proposed ${ }^{4}$ for the growth of smoother $\mathrm{AlGaAs}$ in the forbidden temperature gap (FTG) where the Ga sticking coefficient is close to unity and the Sb incorporation rate is close to zero. Since most of the device applications use large $\mathrm{Al}$ mole fraction alloys, in this work we chose to study the Sb-mediated growth of Si-doped $\mathrm{Al}_{0.65} \mathrm{Ga}_{0.35} \mathrm{As}$ layers with emphasis on the optimizing both the electrical and optical properties for device applications.

A set of Si-doped $\left(N_{\mathrm{Si}}=2 \times 10^{18} \mathrm{~cm}^{-3}\right) \mathrm{Al}_{0.65} \mathrm{Ga}_{0.35} \mathrm{As}$ samples were grown at various temperatures $(580,610,640$, 670,700 , and $\left.720^{\circ} \mathrm{C}\right)$ and various $\mathrm{Sb} / \mathrm{III}$ flux ratios $(0.00$, $0.005,0.01$, and 0.02 ). The growth was done in a V80H VG MBE system equipped with $\mathrm{Ga}, \mathrm{Al}$, and $\mathrm{Si}$ effusion cells and $\mathrm{As}$ and $\mathrm{Sb}$ valved cracking cells. The samples were grown on

\footnotetext{
a) Author to whom correspondence should be addressed; electronic mail: shane.johnson@asu.edu

${ }^{b}$ Presently at: Lytek Corporation, 4717 East Hilton Avenue, Phoenix, AZ 85034.
}

semi-insulating GaAs (100) substrates starting with a $30 \mathrm{~nm}$ GaAs buffer layer, followed by a 200-nm-thick undoped $\mathrm{Al}_{0.65} \mathrm{Ga}_{0.35} \mathrm{As}$ spacer layer and a 1000 -nm-thick, Si doped $\mathrm{Al}_{0.65} \mathrm{Ga}_{0.35} \mathrm{As}$ layer. The undoped spacer provides a barrier to free-carrier penetration into the GaAs buffer layer, preventing the formation of a two-dimensional electron gas that would adversely impact the electrical measurements. The $\mathrm{Al}_{0.65} \mathrm{Ga}_{0.35}$ As layer was covered with a thin, $10 \mathrm{~nm} n$-GaAs contact layer, whose thickness was chosen to be thick enough to provide electrical contact to the $\mathrm{AlGaAs}$ layer and yet thin enough to not obscure the surface morphology or conductivity of the underlying AlGaAs layer.

The $\mathrm{Sb}$ flux values are given in absolute terms with $\mathrm{Sb} / \mathrm{III}=\mathrm{Sb} /(\mathrm{Ga}+\mathrm{Al})$, where each element is in units of incident atoms per unit area per unit time. The As/III overpressure was 1.5 for the lower growth temperatures and 2.0 for the higher growth temperatures. The $\mathrm{Al}_{0.65} \mathrm{Ga}_{0.35} \mathrm{As}$ layers are random alloy and were grown under a group- $\mathrm{V}$ stabilized $2 \times 4$ surface reconstructed for both $\mathrm{Sb}$-mediated and $\mathrm{Sb}$-free growth. The growth (substrate) temperatures were accurately determined from the band edge of the substrate using diffuse reflection spectroscopy; ${ }^{5}$ the substrate thermocouple reading was about $100^{\circ} \mathrm{C}$ higher. The samples were investigated using atomic force microscopy (AFM), x-ray diffraction (XRD), secondary ion mass spectroscopy (SIMS), and the Hall-effect measurements in the Van der Pauw contact geometry.

The surface morphology of each sample was examined by AFM and the rms surface roughness obtained from these measurements is reported in Fig. 1 for the various Sb fluxes and growth temperatures. The smoothing effect of the $\mathrm{Sb}$ surfactant in the FTG is evident, and the amount of Sb flux required for smoothing tends to increase with the substrate temperature. A Sb/III flux ratio of 0.005 is sufficient for substrate temperatures below $650{ }^{\circ} \mathrm{C}$, while a Sb/III flux ratio of 0.01 to 0.02 is necessary for substrate temperatures greater than $650^{\circ} \mathrm{C}$.

The XRD measurements reveal that about $40 \%$ of the 


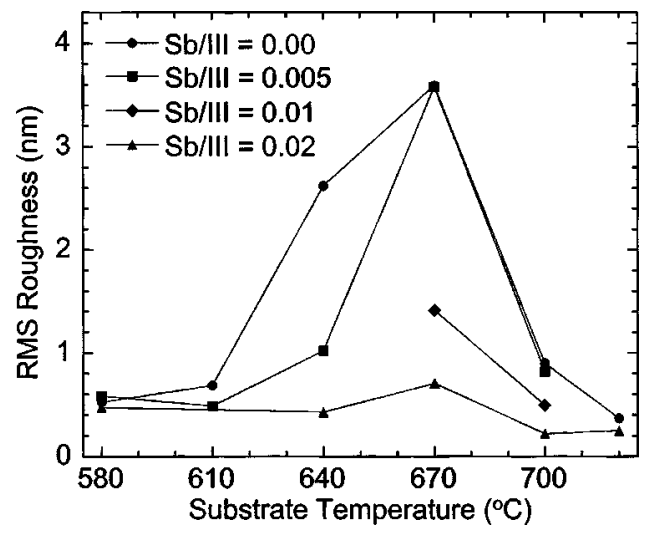

FIG. 1. rms surface roughness of 1.2- $\mu$ m-thick $\mathrm{Al}_{0.65} \mathrm{Ga}_{0.35}$ As layers grown at various $\mathrm{Sb} / \mathrm{III}$ flux ratios and substrate temperatures.

incident $\mathrm{Sb}$ flux is incorporated at the lowest substrate temperature $\left(580^{\circ} \mathrm{C}\right)$. As the substrate temperature increases the $\mathrm{Sb}$ incorporation decreases exponentially, quickly dropping below concentrations measurable by XRD. Therefore, to determine the temperature dependence of the Sb incorporation (or sticking coefficient), SIMS measurements were done on the samples grown under the highest (0.02) $\mathrm{Sb} / \mathrm{III}$ flux. The $\mathrm{XRD}$ measurements are used to assign absolute numbers to the SIMS data shown in Fig. 2. The Sb concentration (lefthand axis) and the Sb sticking coefficient (right-hand axis) decrease by two orders of magnitude over the temperature range shown, resulting in a low (but non zero) $\mathrm{Sb}$ concentration of about $2 \times 10^{18} \mathrm{~cm}^{-3}$ in samples grown at $700^{\circ} \mathrm{C}$. Even at the highest growth temperatures, $\mathrm{Sb}$ is incorporated as an isoelectronic dopant. The Sb sticking coefficient exhibits an Arrhenius behavior (solid line fit to the data) with a characteristic energy of $2.76 \pm 0.15 \mathrm{eV}$. The equation with the best-fit parameters is shown in the Fig. 2, where $k T$ is in units of absolute temperature. The constant in front of exponential is $8800 \mathrm{~cm}^{-3}$ for $\mathrm{Sb}$ concentration (left-hand scale) and $2.0 \times 10^{-15} \%$ for $\mathrm{Sb}$ sticking coefficient (right-hand scale).

Figure 3 shows the room-temperature Hall mobility of Si-doped $\left(N_{\mathrm{Si}}=2 \times 10^{18} \mathrm{~cm}^{-3}\right) \mathrm{Al}_{0.65} \mathrm{Ga}_{0.35} \mathrm{As}$ for the set of samples just discussed. The electron mobility increases with growth temperature and is enhanced by Sb codoping. Remarkably, at the lower growth temperatures at which the $\mathrm{Sb}$ levels are large $\left(\sim 10^{20} \mathrm{~cm}^{-3}\right), \mathrm{Sb}$ as an isoelectronic dopant

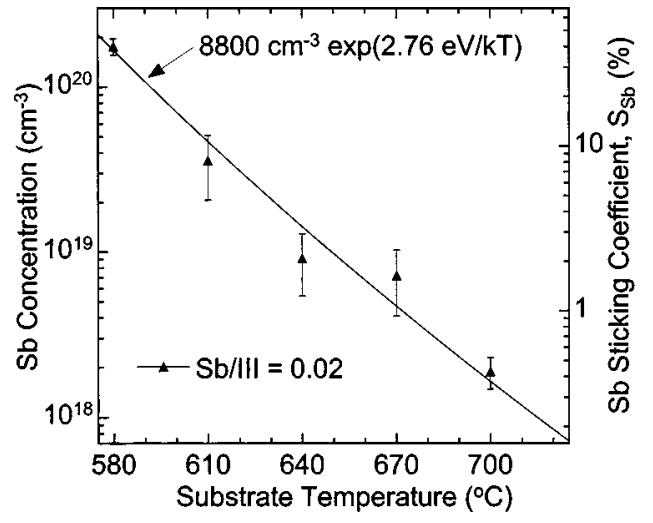

FIG. 2. Sb concentration and sticking coefficient derived from SIMS and XRD data for $n-\mathrm{Al}_{0.65} \mathrm{Ga}_{235} \mathrm{As}$ grown at various temperatures and a $\mathrm{Sb} / \mathrm{III}$ flux ratio of 0.02 .

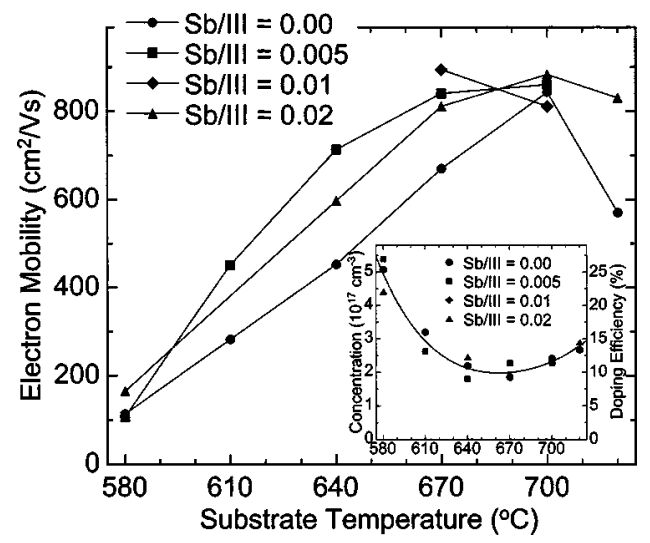

FIG. 3. Electron mobility of $1.0-\mu$ m-thick Si-doped $\mathrm{Al}_{0.65} \mathrm{Ga}_{0.35} \mathrm{As}$ layers grown at various $\mathrm{Sb} / \mathrm{III}$ flux ratios and substrate temperatures. The electron concentration is shown in the inset.

still improves the electron mobility, indicating that Sb codoping does not add to electron scattering. In the 640 to $670{ }^{\circ} \mathrm{C}$ growth temperature range, the optimal $\mathrm{Sb}$ codoping level is about $3 \times 10^{18} \mathrm{~cm}^{-3}(\mathrm{Sb} / \mathrm{III}=0.005$ to 0.01$)$. The mobility decreases at the highest growth temperature $\left(720^{\circ} \mathrm{C}\right)$ because, according to the XRD measurements, the $\mathrm{Al}$ mole fraction increases from 0.65 to 0.70 caused by a reduction in Ga sticking from close to unity at $700{ }^{\circ} \mathrm{C}$ to 0.8 at $720^{\circ} \mathrm{C}$.

Although growth temperature and $\mathrm{Sb}$ codoping have a dramatic affect on the electron mobility; the overall contribution to the conductivity is not as spectacular because of the strong dependence of the electron concentration (doping efficiency) on growth temperature shown in the inset of Fig. 3. The free electron concentration is given on the left-hand axis and ranges from a high of $n=5 \times 10^{17} \mathrm{~cm}^{-3}$ to a low of $n$ $=2 \times 10^{17} \mathrm{~cm}^{-3}$, and the Si doping efficiency (defined as $\left.n / N_{\mathrm{Si}}\right)$ is given on the right-hand axis. The trend in the doping efficiency (shown by the solid line) seems to be independent of the Sb codoping levels and has a minimum of $10 \%$ at $660^{\circ} \mathrm{C}$, which is right in the middle of FTG. The best doping efficiency $(25 \%)$ occurs at the lowest growth temperature $\left(580^{\circ} \mathrm{C}\right)$. Notwithstanding the decline in electron concentration, the conductivity of the AlGaAs layer improves with growth temperature, as shown by the plot of sheet resistance versus growth temperature and Sb flux in Fig. 4. Overall, the sheet resistance decreases at a rate of $5 \Omega /{ }^{\circ} \mathrm{C}$ as the growth

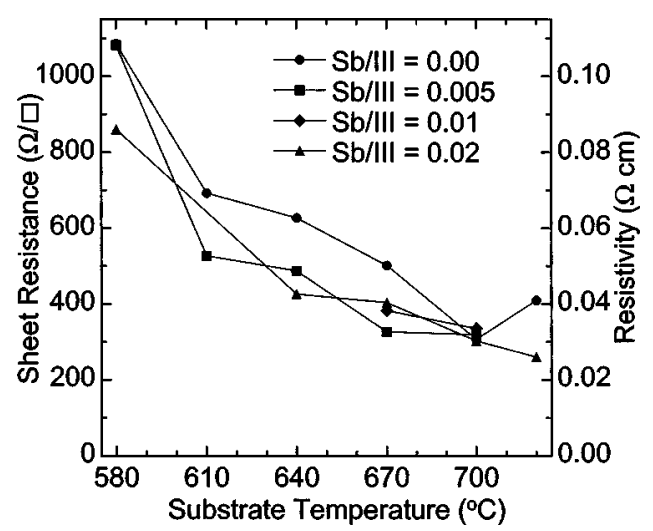

FIG. 4. Sheet resistance of 10 - $\mu$ m-thick Si-doped $A l_{0.65} \mathrm{Ga}_{0.35} \mathrm{As}$ layers grown at various $\mathrm{Sb} / \mathrm{III}$ flux ratios and substrate temperatures. 
temperature increases, and is further reduced by $120 \Omega$ on average when $\mathrm{Sb}$ codoping is present.

$\mathrm{Sb}$ acts as both a surfactant and an isoelectronic dopant in AlGaAs. As a surfactant, Sb provides improved surface morphology with the most dramatic improvement occurring in the forbidden growth temperature gap. During Sbmediated growth a steady-state surface population of $\mathrm{Sb}$ is maintained, enhancing the surface diffusion kinetics of the $\mathrm{Ga}$ and $\mathrm{Al}$ adatoms. The three-dimensional morphology of $\mathrm{AlGaAs}$ layers grown in the forbidden temperature gap is thought to originate from less than ideal $\mathrm{Ga}$ and $\mathrm{Al}$ transport caused by oxygen gettering on the surface, ${ }^{6}$ strong anisotropy of surface diffusion, ${ }^{7}$ the strong $\mathrm{Al}-\mathrm{As}$ bond, ${ }^{8}$ and diffusion barriers at island edges. ${ }^{9}$ At higher temperatures above the FTG, Ga and Al diffusion is enhanced, resulting in smoother films. Below the FTG, surface impurities are thought to be more readily incorporated interfering less with surface mobility and the Al adatoms tend to stay put avoiding roughening due to anisotropic diffusion.

As an isoelectronic dopant, $\mathrm{Sb}$ yields higher electron mobility and lower sheet resistance for $n$-AlGaAs. Isoelectronic doping reduces deep levels which improves the material properties of Si-doped AlGaAs where deep-level traps are not simply arsenic or gallium vacancies, but possibly impurities or gallium/arsenic related complexes. ${ }^{10}$ Furthermore, isoelectronic doping reduces unintentional impurities and dislocation density in III-V materials. ${ }^{11}$ The low doping efficiency of $\mathrm{Si}$ in $\mathrm{Al}_{0.65} \mathrm{Ga}_{0.35} \mathrm{As}$ is largely because $\mathrm{Si}$ is a relatively deep donor, $\sim 120 \mathrm{meV}$ for $\mathrm{Al}_{0.65} \mathrm{Ga}_{0.35} \mathrm{As},{ }^{12}$ and to a lesser extent because some $\mathrm{Si}$ atoms incorporate as acceptors or form DX centers ${ }^{13}$ in AlGaAs. Furthermore, the doping efficiency is independent of $\mathrm{Sb}$ codoping and is remarkably dependent on growth temperature (see Fig. 3 inset); indicating that the amphoteric nature of $\mathrm{Si}$ and the for- mation of DX centers in AlGaAs depend on growth temperature. Compensation by defects is another possibility, in which case the defect formation would have to depend only on temperature, and not on Sb codoping or surface morphology.

In conclusion, the Sb-mediated growth of $\mathrm{Al}_{0.65} \mathrm{Ga}_{0.35} \mathrm{As}$ improves both electrical properties and surface morphology, where $\mathrm{Sb}$ as an isoelectronic dopant improves electron mobility and $\mathrm{Sb}$ as a surfactant reduces surface roughness. In both cases, the most impressive improvement occurs in $620-680^{\circ} \mathrm{C}$ temperature region, effectively eliminating the forbidden temperature gap for device growth. The use of $\mathrm{Sb}$-mediated growth has resulted in improved laser device performance, most notably in VCSELs.

${ }^{1}$ H. Morkoç, T. J. Drummond, W. Kopp, and R. Fischer, J. Electrochem. Soc. 129, 824 (1982).

${ }^{2}$ W. I. Wang, S. Judaprawira, C. E. C. Wood, and L. F. Eastman, Appl. Phys. Lett. 38, 708 (1981).

${ }^{3}$ R. A. Stall, J. Zilko, V. Swaminathan, and N. Schumaker, J. Vac. Sci. Technol. B 3, 524 (1985).

${ }^{4}$ R. Kaspi, K. R. Evans, D. C. Reynolds, J. Brown, and M. Skowronski, Mater. Res. Soc. Symp. Proc. 379, 79 (1995).

${ }^{5}$ S. R. Johnson, C.-H. Kuo, M. D. Boonzaayer, W. Braun, U. Koelle, Y.-H. Zhang, and J. A. Roth, J. Vac. Sci. Technol. B 16, 1502 (1998).

${ }^{6}$ N. Chand, S. N. G. Chu, and M. Geva, Appl. Phys. Lett. 59, 2874 (1991).

${ }^{7}$ R. Mirin, M. Krishnamurthy, J. Ibbetson, J. English, and A. Gossard, J. Cryst. Growth 127, 908 (1993).

${ }^{8}$ F. Alexandre, L. Goldstein, G. Leroux, M. C. Joncour, H. Thibierge, and E. V. K. Rao, J. Vac. Sci. Technol. B 3, 950 (1985).

${ }^{9}$ J. M. Van Hove and P. I. Cohen, Appl. Phys. Lett. 47, 726 (1985).

${ }^{10}$ K. D. Jamison, H. C. Chen, A. Bensaoula, W. Lim, L. Trombetta, and A. Igntiev, J. Vac. Sci. Technol. A 7, 606 (1989).

${ }^{11}$ V. K. Bazhenov and V. I. Fistul, Sov. Phys. Semicond. 18, 843 (1984).

${ }^{12}$ N. Chand, T. Henderson, J. Klem, W. T. Masselink, R. Fischer, Y.-C. Chang, and H. Morkoc, Phys. Rev. B 30, 4481 (1984).

${ }^{13}$ A. Leuther, A. Förster, H. Lüth, H. Holzbrecher, and U. Breuer, Semicond. Sci. Technol. 11, 766 (1996). 